\title{
Metodología para la elaboración de herramientas articuladoras de procesos financieros en entidades públicas. Estudio de caso
}

\author{
Methodology for the development of tools coordinator \\ of financial processes in public entities. Case Study
}

Recibido: 27-11-2017 • Aprobado:11-06-2018 • Página inicial: 119 - Página final: 153

\section{Doralba Castrillón Monsalve*}

Resúmen: este artículo resultado de investigación magisterial, tiene por objeto determinar una metodología para la construcción de una herramienta financiera que permita la articulación de los resultados de los procesos de Presupuesto, Contabilidad y Tesorería en una Institución Pública del Departamento de Antioquia como caso tipo. Para ello, se analizó la articulación de los procesos financieros de presupuesto, contabilidad y tesorería; se presentó una propuesta que facilite la interpretación de los resultados de los tres procesos financieros para su cierre fiscal y se establecieron indicadores de gestión para la toma de decisiones del proceso financiero. Ello permite mejorar la gestión administrativa y financiera, puesto que permite entregar al Sistema Integrado de Información Financiera (SIIF) de los entes de control informes depurados y revisados, aportando integridad y transparencia al manejo administrativo, en cumplimiento de las funciones de cometido estatal.

Palabras clave: herramientas financieras, gestión administrativa y financiera, entidades públicas, procesos financieros.
Abstrat: This article result of magisterial research, aims to identify a methodology for the construction of a financial tool that allows the articulation of the results of the processes of budgeting, accounting and treasury in a public institution, Department of Antioquia as case type. To do this, we analyzed the articulation of the financial processes of budget, accounting and treasury services; a proposal was submitted to facilitate the interpretation of the results of the three financial processes for closing the prosecutor and indicators were developed management for decision-making of the financial process. This allows you to improve the administrative and financial management, since it makes it possible to deliver to the Integrated Financial Information System (SIIF) of control agencies and debugged reports reviewed, providing integrity and transparency to the administrative management, in compliance with the functions of committed state.

Keywords: Financial tools, administrative and financial management, public entities, financial processes.

JEL: D52 - G29

\footnotetext{
* Magister en Administración, Especialista en Gestión Financiera Empresarial y Admistradora de Empresas. Líder de Presupuesto del Tecnológico de Antioquia, Medellín - Colombia. 


\title{
Méthodologie pour l'élaboration d'outils articuladoras de processus financiers dans des entités publiques. Étude de cas
}

Résumé: cet article résultat de recherche magisterial, a pour objet de définir une méthodologie pour la construction d'un outil financière qui permette l'articulation des résultats des processus de budget, de comptabilité et de trésorerie dans une institution publique du Département d'Antioquia comme cas type. Pour cela, on a analysé l'articulation des processus financiers du budget, de comptabilité et de trésorerie; il a présenté une proposition qui facilite l'interprétation des résultats des trois processus financiers pour leur fermeture procureur et ont été des indicateurs de gestion pour la prise de décisions du processus financier. Cela permet d'améliorer la gestion administrative et financière, car elle permet de livrer au Système intégré d'information financière (SIIF) des collectivités de contrôle rapports purifiés et révisés, en apportant de l'intégrité et la transparence de la gestion administrative, dans le respect des fonctions de commis d'État.

Mots-clés: outils financiers, de la gestion administrative et financière, des entités publiques, des processus financiers.

\section{Metodologia para o desenvolvimento de ferramentas coordenador de processos financeiros em entidades públicas. Estudo de caso}

\begin{abstract}
Resumo: este artigo resulta de pesquisa magisterial, tem o objetivo de identificar uma metodologia para a construção de um instrumento financeiro que permite a articulação dos resultados dos processos de orçamentação, contabilidade e tesouraria de uma instituição pública, departamento de Antioquia, como tipo de caso. Para isso, analisouse a articulação dos processos de orçamento, contabilidade e tesouraria serviços; uma proposta foi apresentada para facilitar a interpretação dos resultados dos três processos financeiros para fechar o procurador e indicadores de gestão foram desenvolvidos para a tomada de decisão do processo financeiro. sto permite-lhe melhorar a gestão administrativa e financeira, uma vez que torna possível para entregar ao Sistema Integrado de Informações Financeiras (SIIF) das agências de controle e relatórios de depurado revista, com integridade e transparência para a gestão administrativa, em conformidade com as funções de estado.
\end{abstract}

Palavras-chave: instrumentos financeiros, administrativos e de gestão financeira, entidades públicas, processos financeiros. 


\section{Introducción}

La formulación de planes de desarrollo y planes de acción por programas y por proyectos son básicos en el sector público, donde la programación y el control de esta actividad exigen una larga preparación profesional en el análisis financiero, dado que este sector debe enfrentarse a la escasez de recursos, porque por mucho dinero que tenga disponible siempre las necesidades son mayores y se requiere que los gobiernos prioricen sus objetivos en el tiempo para lograr una acertada toma de decisiones.

El Tecnológico de Antioquia IU, del orden Departamental, debe cumplir con normas gubernamentales en la asignación de los recursos para llevar a cabo las estrategias encaminadas al logro de los objetivos propuestos en el plan de acción y dentro del marco de los planes y políticas públicas departamentales y nacionales, actuando en forma lógica entre las alternativas y teniendo pleno conocimiento de las consecuencias que entraña cada decisión. Para lograr ese conocimiento debe recopilar información administrativa, cualitativa y cuantitativa para analizarla y trasmitirla en forma sistemática con el objetivo único de repartir en varias direcciones los recursos financieros.

A nivel gerencial en la institución la toma de decisiones exige rapidez y seguridad en el control de las operaciones presupuestales, contables y de tesorería, dando cumplimiento a la política gerencial de que esta información es útil, confiable y se vuelve significativa porque prevalece la importancia en el manejo transparente de los recursos.

La realización de la metodología para la homologación de los procesos financieros: Presupuesto, Contabilidad y la Tesorería, al finalizar un periodo determinado, es pertinente porque permitirá identificar las características para la elaboración de una herramienta financiera que cobre importancia como apoyo a las decisiones estratégicas mostrando la identificación de los procesos y los mecanismos para la refrendación de la información que se requiera de una manera comprensible a la luz de los procedimientos; es por esto que se tomarán resultados desde los informes gerenciales como son la ejecución presupuestal, el balance general y el movimiento de caja de un periodo determinado y se confrontarán mediante el análisis operativo de las respectivas transacciones para encontrar las inconsistencias y las explicaciones a los diferentes resultados.

Con los resultados de este trabajo se contribuye al objetivo de realizar gestión financiera para un desarrollo sostenible, porque desarrolla en forma sistemática 


\section{Contexto castrimeno.}

y dinámica, el ejercicio financiero aportando a la comprensión y al análisis de los resultados enmarcados con las normas legales y con la transparencia exigida por el sector público.

\section{Metodología}

\section{Tipo de Estudio}

Se han seleccionado varios tipos de estudio, así:

Investigación descriptiva (Hernández, 2003), porque se recolectará la información escrita que exista sobre los registros contables, presupuestales y de tesorería suministrada por los respectivos departamentos del área financiera.

Investigación comparativa (Hernández, 2003), porque tiene como objetivo lograr la identificación de diferencias o semejanzas entre los tres elementos del proceso financiero (Ejecuciones Presupuestales, Balance General y Movimiento de Caja) y analizar las inconsistencias encontradas.

Investigación analítica (Hernández, 2003), porque tiene como objetivo analizar los diferentes documentos que intervienen en los tres procesos del área financiera y comprenderlos en términos de sus aspectos menos evidentes al contribuir al análisis financiero, anotando que es posible llevar a cabo un conocimiento de profundidad que descubra y compruebe la articulación de los tres procesos.

Investigación explicativa (Hernández, 2003), porque se pretende detectar las relaciones entre los tres procesos financieros: Presupuesto, Contabilidad y Tesorería, mediante la refrendación de los mismos.

\section{Tipos y fuentes de información}

Las fuentes de información que se utilizaron son: primarias y secundarias. Las fuentes de información primarias se fundamentaron en una encuesta aplicada y una entrevista que se hizo a los profesionales universitarios y directivos que intervienen en el proceso financiero de la institución Universitaria.

Se realizó una encuesta ${ }^{1}$ y se aplicó a los 17 funcionarios del Tecnológico de Antioquia IU que intervienen en el proceso financiero y que envían información

1 El cuestionario que se aplicó a través de la herramienta Docs.google que permite agilizar el envío, la respuesta y el análisis de la información. 
a los diferentes entes de control del sector público, con la finalidad de identificar y caracterizar los conceptos, los elementos y las variables que pueden influir en la homologación de información financiera.

La encuesta se aplicó y con las respuestas se logró establecer cómo los ingresos, gastos, costos, egresos, flujo de caja, cuentas por pagar, reservas presupuestales, registro de obligaciones, facturas, afectan los diferentes resultados arrojados en el presupuesto, en la contabilidad y en la tesorería.

Una escala de Likert consta de ítems - afirmaciones, que se consideran relevantes para el asunto a evaluar. Estas afirmaciones expresan aprobación o rechazo al objeto de estudio. Los sujetos responden a estas afirmaciones seleccionando un punto en una gradación del continuo asentamiento-rechazo (aprobación total, aprobación con ciertos reparos, posición no definida, desaprobación en ciertos aspectos, desaprobación total).

Por otro lado, se realizó una entrevista estructurada con el Rector y la Directora Administrativa de la Institución Universitaria, para tener un concepto más administrativo y gerencial, sobre cómo se interpretan los estados financieros y cómo será el deber ser de dicho proceso, que muestre la eficiencia y la eficacia administrativa ante el personal interno y los entes de control que la auditan. El tema de la entrevista surge a partir del análisis de la información de las encuestas, porque era necesaria más profundidad en algunos temas específicos.

El instrumento utilizado es una escala construida según la metodología propuesta por Rensis Likert, porque es apropiada para la medición de actitudes frente a los fenómenos sociales que se estudian. Se envió a los empleados en forma virtual utilizando la plataforma Google Docs.

La entrevista se tiene debidamente documentada; sin embargo, por efectos de confidencialidad de la información, solamente se menciona y la respuesta se utilizará para fundamentar la propuesta para la solución al problema planteado. De la entrevista se sacaron conclusiones sobre el cumplimiento de las normas a escala Nacional, Departamental e Institucional, y se confirman las variables importantes objeto de estudio en este trabajo.

También se emplearon fuentes de información secundaria; específicamente documentos como ejecuciones presupuestales, balance general, movimiento de caja; además de los soportes de comprobantes de diario, necesarios para sustentar la articulación de los tres procesos al momento de hacer la conciliación como propuesta a la problemática presentada (Méndez, 2011). 


\section{Contexto cassinus o.}

\section{Técnicas e instrumentos}

Los estudios descriptivos acuden a técnicas específicas de recolección de datos, como la observación, las entrevistas y los cuestionarios (Méndez, 2011). Se elaboró una encuesta, de conformidad con los conceptos, elementos y variables planteados.

A través de la observación cualitativa y cuantitativa (Hernández, 2003), se pretende identificar los características que permitan establecer la diferencia entre los respectivos registros de los documentos que intervienen en los componentes del proceso y la gestión financiera que son los conceptos centrales del presente trabajo, permitiendo establecer la relación con los elementos de los mismos y sacar las explicaciones de las diferencias. Esto permite caracterizar la relación entre el proceso financiero que influye directamente en la toma de decisiones.

Los cuestionarios fueron elaborados de una forma estructurada de conformidad con los conceptos y variables a analizar; las respuestas se hicieron más para conceptualizar de acuerdo a la percepción y la experiencia propia de cada uno de los profesionales.

Para establecer los conocimientos del problema planteado en el manejo de la información financiera, se contó con documentos de experiencias en auditorías pasadas por parte de los entes de control (Contraloría General de la República, Ministerio de Educación Nacional y Contraloría Departamental, entre otros).

De los cuestionarios se obtuvo el conocimiento y la idoneidad para manejar el tema financiero, pero por cada uno de los procesos por separado y las inconsistencias encontradas por los entes de control en el momento de hacer la respectiva refrendación del proceso financiero, permitiendo detallar las variables implicadas en el análisis de los resultados obtenidos, como son: el alcance, la legalidad, la confiabilidad, la oportunidad, la transparencia, la razonabilidad, verificabilidad, la relevancia, materialidad, comprensibilidad, y consistente en el manejo de los recursos financieros.

Esta información incluye estados financieros estadísticos, informes, ejecuciones presupuestales, movimientos de caja, además de los documentos que los componen respectivamente y que son importantes debido a que la información necesaria para este trabajo, generalmente versa sobre asuntos de actualidad que afectan a una institución; en particular es de interés grupal. 


\section{Resultados}

\section{Análisis del proceso financiero en el Tecnológico de Antioquia Institución Universitaria}

Para que las respuestas de esta encuesta fueran más objetivas, se reunieron las personas que intervienen directamente en el proceso financiero con el fin de proyectar algunos documentos del proceso financiero necesarios de aclarar, antes de responder algunas preguntas del instrumento.

Para la elaboración de las gráficas proyectadas se contó con la información presentada en los estados financieros (balance general, ejecución presupuestal y movimiento de caja) al finalizar un periodo determinado en este caso vigencia fiscal 2012, y los resultados fueron los siguientes:

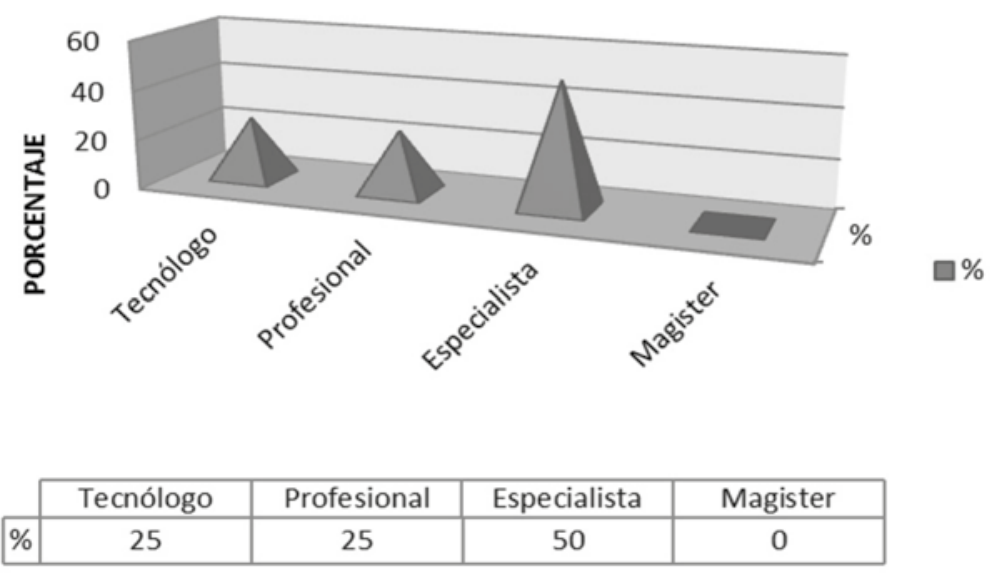

Figura 1. Nivel de educación del personal del área financiera

Elaboración propia, 2017.

Se encontró que el personal que interviene en el área financiera tiene un nivel de educación alto y se convierte en una fortaleza para la institución, porque facilita el proceso por el conocimiento y la idoneidad para manejar el tema financiero y el porcentaje mayor $(50 \%)$ son los que tienen la máxima "responsabilidad" de la entrega oportuna de la información (Figura 1). 


\section{Contexto casstion o.}

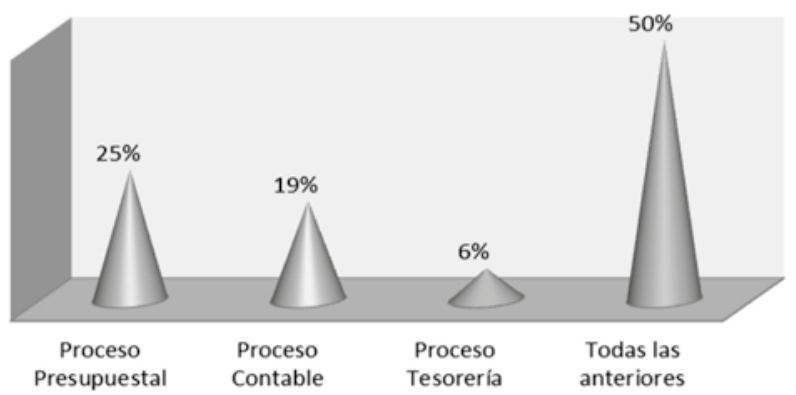

Figura 2. Conocimiento de las características de los documentos registrados en el proceso financiero

Elaboración propia, 2017.

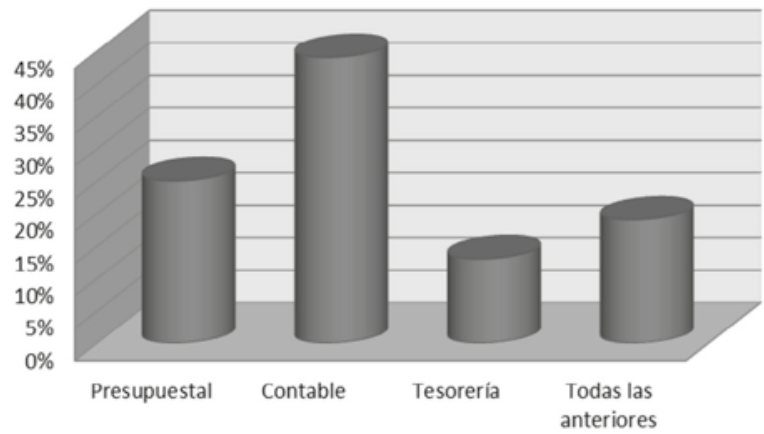

口PROCESO FINANCIERO

Figura 3. Conocimiento de la normatividad del sector público

Elaboración propia, 2017.

$$
\pm \mathrm{SI}=\mathrm{NO}
$$

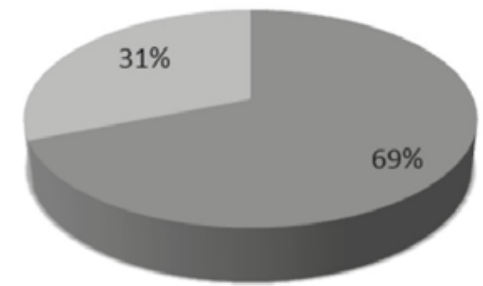

Figura 4. Conocimiento del alcance en el proceso financiero de los documentos que registra Elaboración propia, 2017. 
En las Figuras 3 y 4 aclarados por los mismos participantes, la respuesta fue tomada desde el proceso al cual pertenece; es decir, conocen las características de los documentos registrados, pero desde su función que lo hace directamente responsable; de igual forma conocen la normatividad vigente minimizando el riesgo de un ordenamiento jurídico penal para la Institución Universitaria, por el incumplimiento de la parte "legal", al generar informes para los diferentes entes de control.

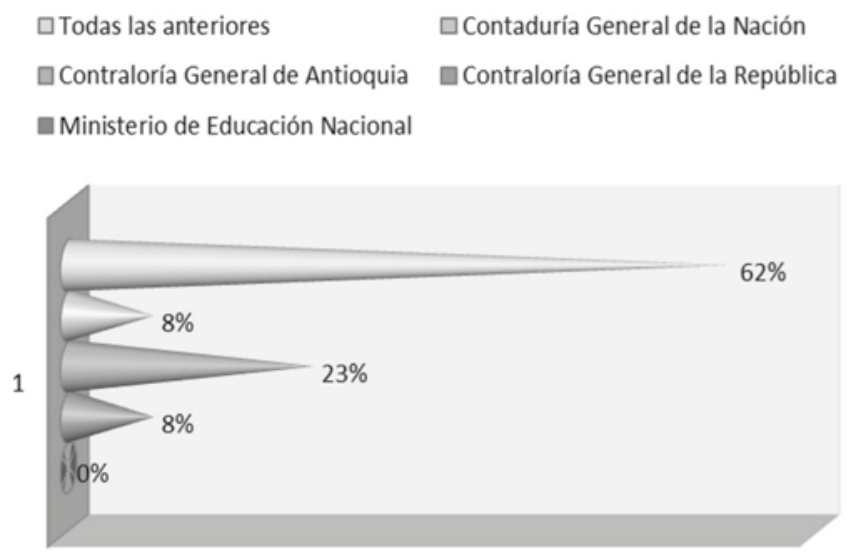

Figura 5. Entes de Control a quienes se envía información financiera Elaboración propia, 2017.

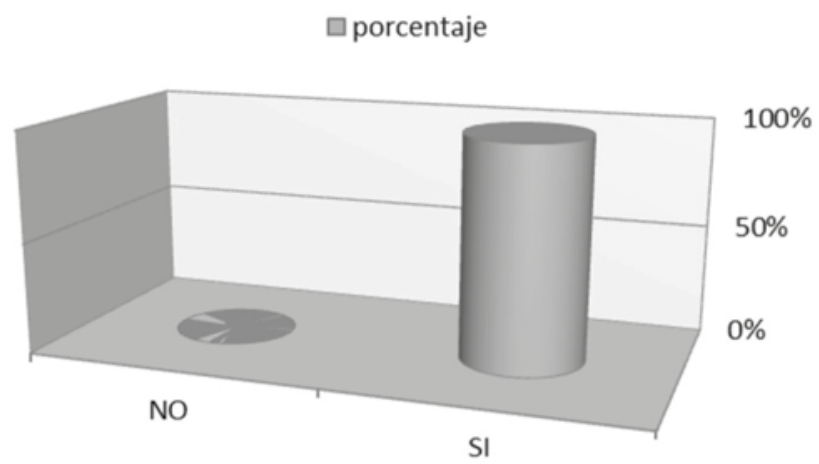

Figura 6. Oportunidad para presentar informes por parte del personal del área financiera Elaboración propia, 2017. 


\section{Contexto castrimen, o.}

$\square S I \square N O$

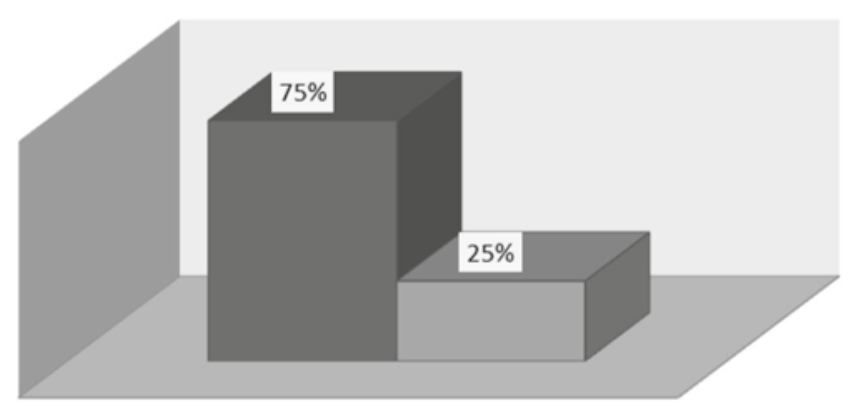

Figura 7. Identificación de las transacciones que generan reportes que se constituyen en proveedores del proceso

Elaboración propia, 2017.

La mayoría del personal del área financiera identifica las transacciones que generan reportes y que a la vez se constituyen en proveedores del proceso financiero, favoreciendo la "confiabilidad" de los resultados generados en los reportes y la "verificación" de la información porque permite la consistencia de la misma y la comprensión al momento de generar reportes.

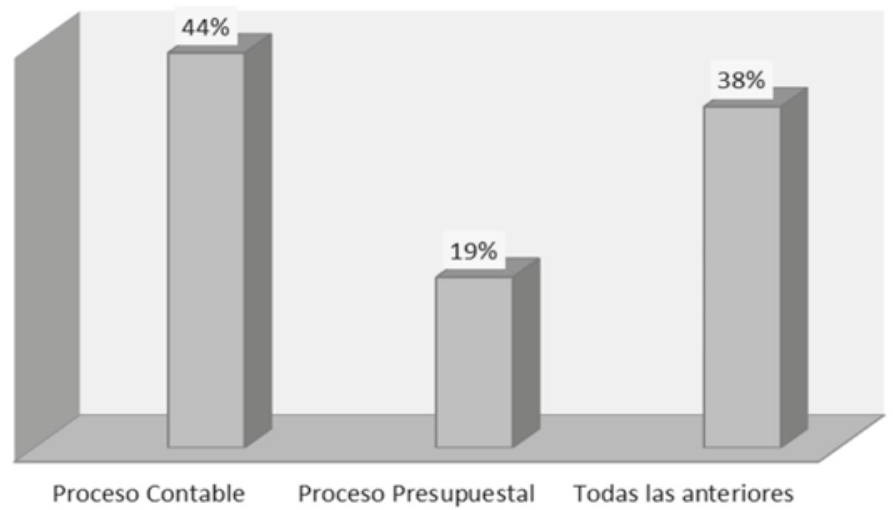

Figura 8. Indicadores establecidos con su respectiva interpretación

Elaboración propia, 2017.

No se tienen establecidos los indicadores el área financiera como lo muestra la figura, porque se analizan dependiendo de la exigencia de la entidad que los solicite. 


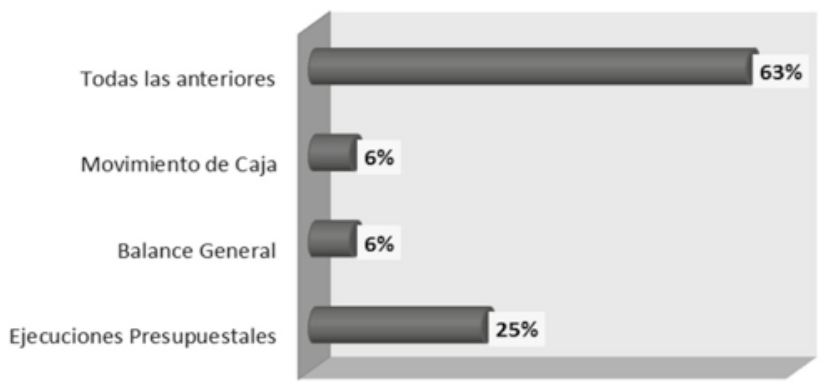

Figura 9. Presentación de cifras homogéneas

Elaboración propia, 2017.

El área financiera del Tecnológico de Antioquia IU, se asegura de presentar cifras homogéneas a quien las solicite, porque es producto de un proceso "racional" y sistemático, que reconoce y revela las transacciones hechas y operaciones con base en un conjunto de procesos homogéneos; comparable y transversal de principios y normas técnicas y procedimientos.

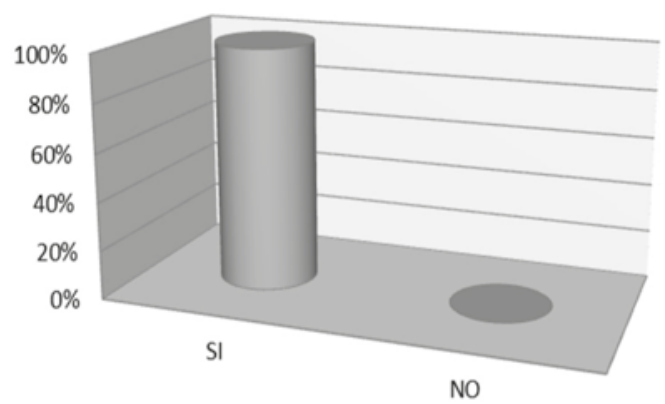

Figura 10. Utilización de la información con propósitos de gestión Elaboración propia, 2017.

Los informes financieros son utilizados con el propósito de medir la Gestión Administrativa que sirve para evaluar la situación financiera, la "eficiencia y la eficacia" de los recursos mediante los indicadores de gestión.

Para responder la pregunta: ¿Usted conoce la metodología para hacer el cierre de una vigencia fiscal?, fue necesario proyectar la siguiente información:

- Balance de General del año 2012.

- Ejecuciones Presupuestales de Ingresos y Egresos vigencia fiscal 2012.

- Movimiento de caja a 31 de diciembre del año 2012. 


\section{Contexto cassinten . .}

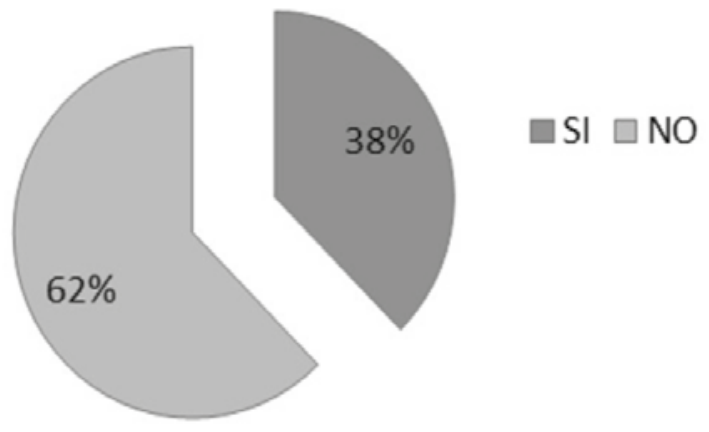

Figura 11. Conocimientos de la metodología para hacer cierre de una vigencia fiscal

Elaboración propia, 2017.

Cada uno de los encuestados respondió la pregunta desde el proceso al cual pertenece pero no a la explicación de las diferencias arrojadas en cada uno de ellos. Llegando a la conclusión de que el $62 \%$ de los profesionales especializados saben hacerlo, pero desde su proceso específico, pero no desde la articulación de los tres procesos.

Los resultados de la Figura, quienes la respondieron positivamente aclararon, que se hace en forma manual, pero no existen los papeles de trabajo arrojados desde el software administrativo; lo que dificulta en cuanto al tiempo invertido en caso de alguna inconsistencia presentada.

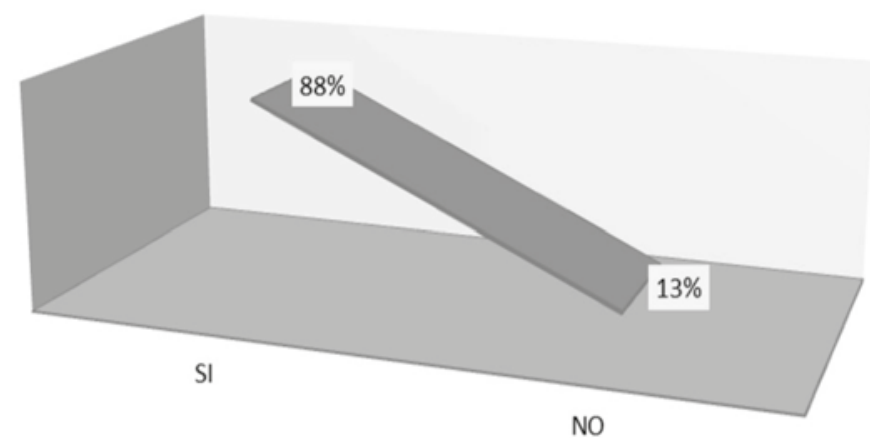

Figura 12. Se hacen conciliaciones de saldos recíprocos entre los procesos presupuestal, Contable y la tesorería

Elaboración propia, 2017. 
¿En el Tecnológico de Antioquia se hacen verificaciones periódicas para comprobar que los registros Presupuestales, Contables y de Tesorería se realizan en forma adecuada y por los valores correctos?

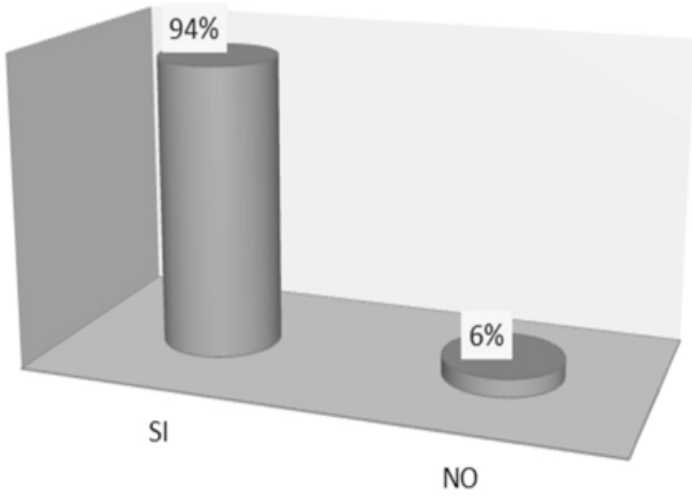

Figura 13. Verificación de los registros presupuestales, contables y de tesorería Elaboración propia, 2017.

Para las respuestas fue necesaria la siguiente ilustración:

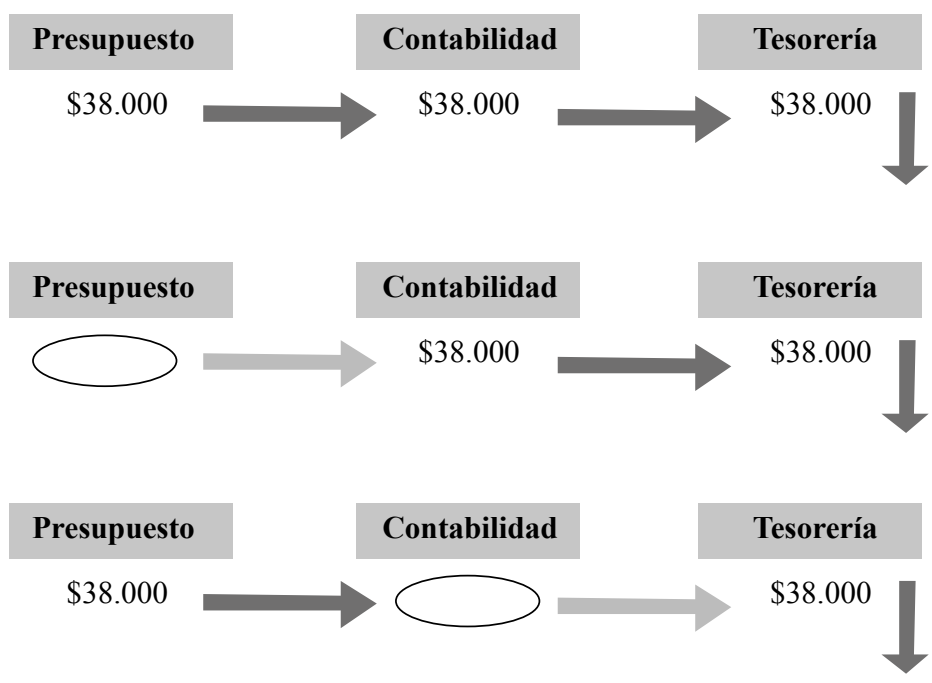

Figura 14. Ejemplo de contabilizacion de una factura de compra

Elaboración propia, 2017. 


\section{Contexto castrimeno.}

\begin{tabular}{|c|c|c|c|c|}
\hline \multicolumn{5}{|c|}{ (DOCUMENTO 07) } \\
\hline $\begin{array}{l}\text { CUENTA } \\
\text { CONTABLE }\end{array}$ & $\begin{array}{c}\text { FACTURA } \\
\text { DOCUEMTTO } 07\end{array}$ & $\begin{array}{l}\text { CENTRO } \\
\text { COSTOS }\end{array}$ & $\begin{array}{l}\text { MOVIMIENTO } \\
\text { DÉBITO }\end{array}$ & MOVIMIENTO CREDITO \\
\hline 14201201 & ACTIVO & & 431.342 .253 & - \\
\hline 24010101 & PASIVO & & - & 431.342 .253 \\
\hline 14221001 & ACTIVO & & 2.672 .000 & $\cdot$ \\
\hline 24010101 & PASIVO & & - & 15.631 .200 \\
\hline 24360301 & PASIVO & & - & 1.837 .000 \\
\hline 24362502 & PASIVO & & - & 1.336 .000 \\
\hline 24362710 & PASIVO & & - & 167.000 \\
\hline 29050201 & PASIVO & & - & 66.800 \\
\hline 29050202 & PASIVO & & - & 100.200 \\
\hline 29050203 & PASIVO & & $\cdot$ & 167.000 \\
\hline 29050205 & PASIVO & & - & 66.800 \\
\hline 51111104 & GASTO & 103304 & 16.700 .000 & - \\
\hline
\end{tabular}

Figura 15. Ejemplo de contabilizacion de una factura de compra

Elaboración propia, 2017.

\begin{tabular}{|c|c|c|c|c|}
\hline \multicolumn{5}{|c|}{ MOVIMIENTO PRESUPUESTAL } \\
\hline CRP & CRP-OB & RUBRO & $\begin{array}{l}\text { CENTRO } \\
\text { DE } \\
\text { COSTOS }\end{array}$ & OBLIGACIÓN \\
\hline 886 & OBLIGACIÓN & A5122 & 104495 & 431.342 .253 \\
\hline 762 & OBLIGACIÓN & A5122 & 103304 & 15.631 .200 \\
\hline \multicolumn{5}{|c|}{ MOVIMIENTO TESORERIA } \\
\hline CHEQUE & PAGO & BANCO & TIPO & VALOR PAGADO \\
\hline 21530 & EROGACIÓN & POPULAR & 2 & 431.342 .253 \\
\hline 21830 & EROGACIÓN & POPULAR & 2 & 19.372 .000 \\
\hline
\end{tabular}

Figura 16. Movimiento presupuestal

Elaboración propia, 2017.

La mayoría, es decir un 94\%, respondió positivamente pero hay que revisar constantemente porque falta parametrizar todas las transacciones para poder entender las diferenciase en los diferentes procesos. 
Todos los registros Contables, Presupuestales y de Tesorería que se realizan en el Tecnológico de Antioquia IU, tienen los respectivos soportes idóneos; es por eso que la información es "verificable"en cualquier momento solicitado y comprensible porque los usuarios se pueden formar un juicio objetivo para que la información este coherente con los resultados (Figura 17).

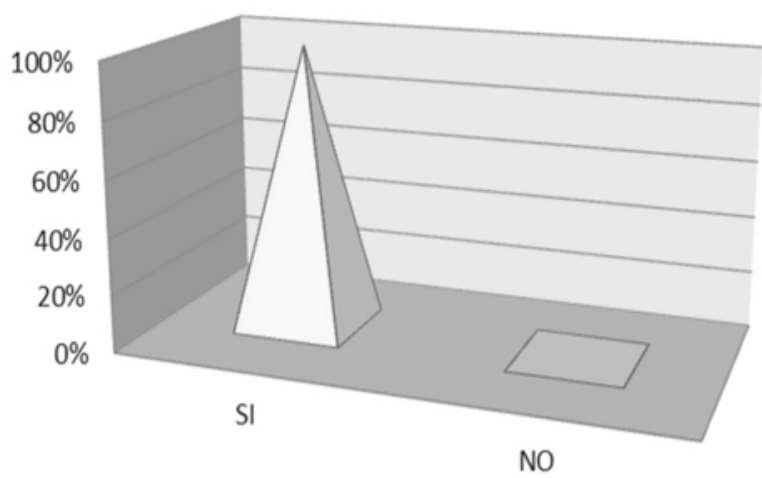

Figura 17. Los registros tienen los mismos soportes idóneos

Elaboración propia, 2017.

La mayoría de las personas que trabajan el área financiera identifican los productos generados de los procesos que se constituyen en soporte de un resultado final para la toma de decisiones; estos son básicamente los que avalúan el proceso desde el proceso del cual es responsable (Figura 18).

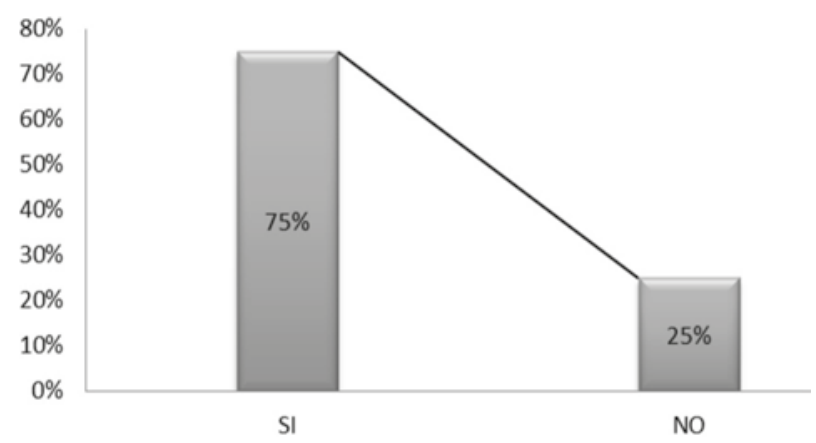

Figura 18. Identificación de los productos generados de los procesos Elaboración propia, 2017. 


\section{Contexto castrimeno.}

Este resultado (Figura 19) muestra la "transparencia" de la información, porque es la misma al momento de su divulgación para los usuarios que la requieran. Este resultado obedece a que los diferentes entes de control piden la misma información pero en formatos diferentes; sin embargo, para conciliarlos se dificulta la respectiva comparación e identificación de los resultados.

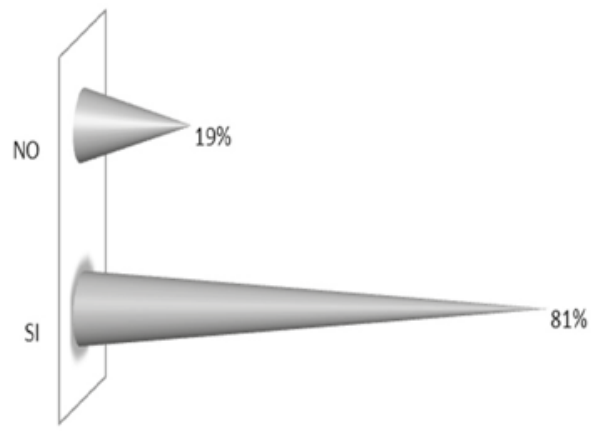

Figura 19. Las cifras en los estados, informes y reportes presupuestales, contables y en los movimientos de caja coinciden

Elaboración propia, 2017.

El Tecnológico de Antioquia IU, cuenta con un área financiera estructurada de conformidad con la complejidad, desarrollo tecnológico y estructura organizacional acorde con la entidad y que se va ajustando a medida que va cumpliendo con el plan de desarrollo Institucional-Departamental (crecimiento) (Figura 20).

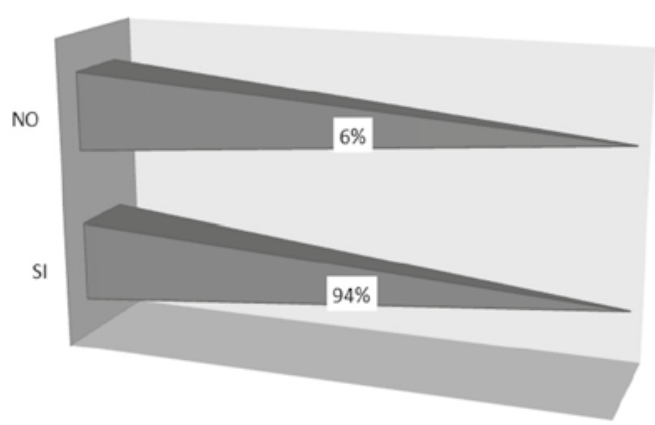

Figura 20. El Área Financiera tiene una estructura acorde a la complejidad, desarrollo tecnológico y organizacional

Elaboración propia, 2017. 
Teniendo en cuenta que el Tecnológico de Antioquia IU, cuenta con un software administrativo que trabaja en línea, pero cada uno de los funcionarios responde o interviene directamente solo por el proceso que le corresponde (Figura 21).

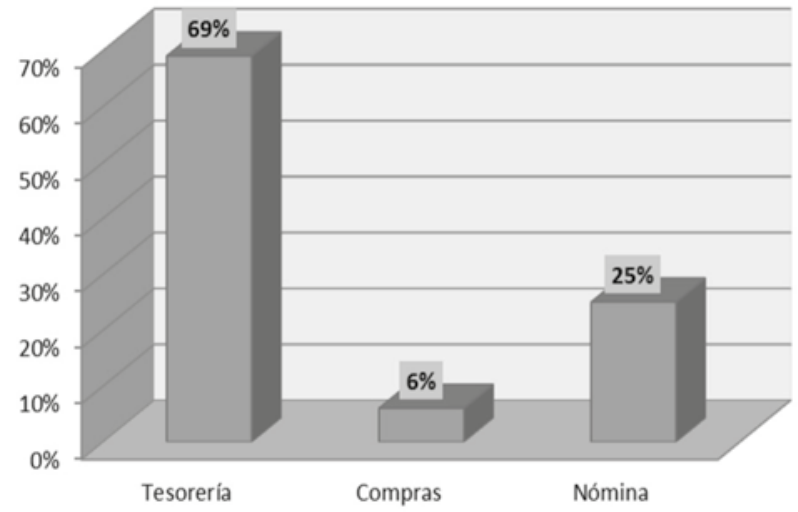

Figura 21. Conocimiento del alcance de la interface en el software administrativo en los diferentes procesos

Elaboración propia, 2017.

Para la pregunta: ¿La información suministrada por el software administrativo del Tecnológico de Antioquia IU, no está debidamente parametrizada y homologada que incluya las partidas extrapresupuestales para los procesos del área financiera?, se explicaron los siguientes casos (Figuras 20, 21 y 22):

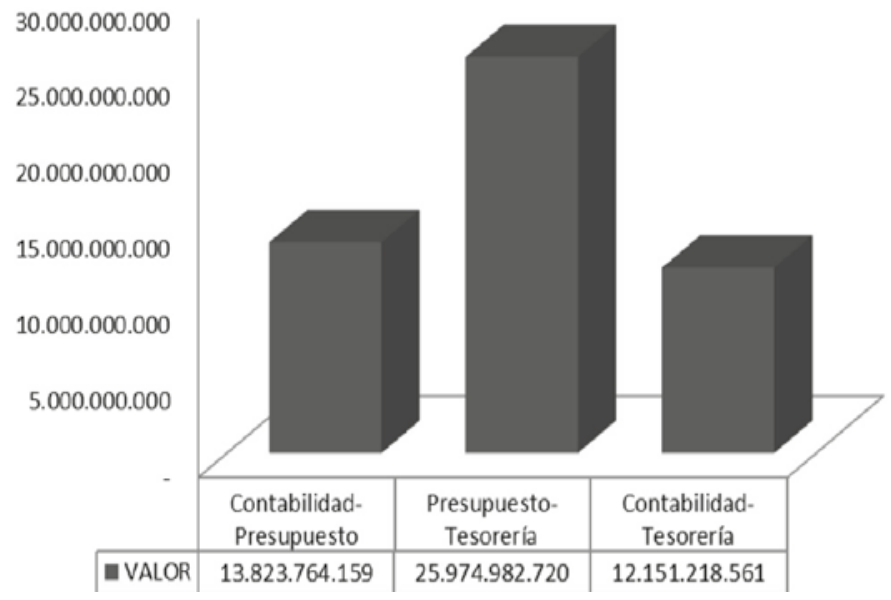

Figura 22. Diferencia ingresos en efectivo

Elaboración propia, 2017. 


\section{Contexto cassminon.}

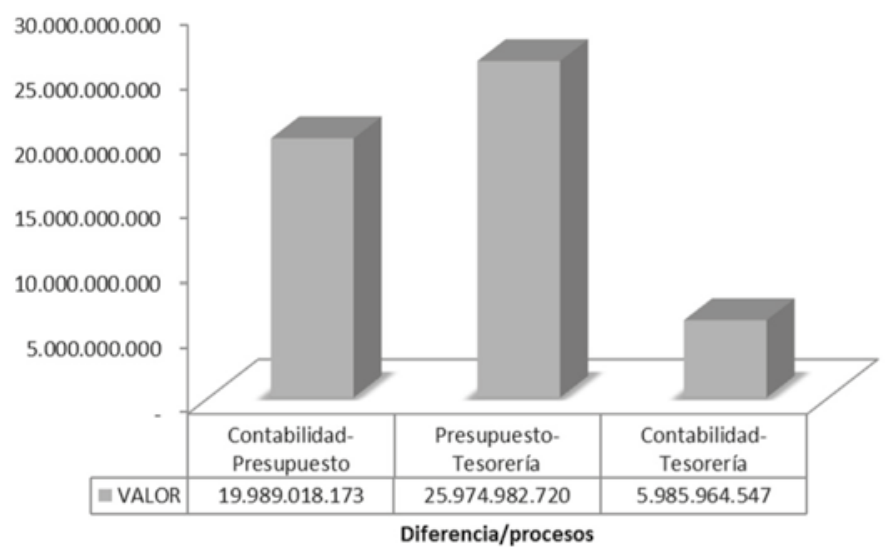

Figura 23. Diferencia entre ingresos causados

Elaboración propia, 2017.

El resultado fue el siguiente:

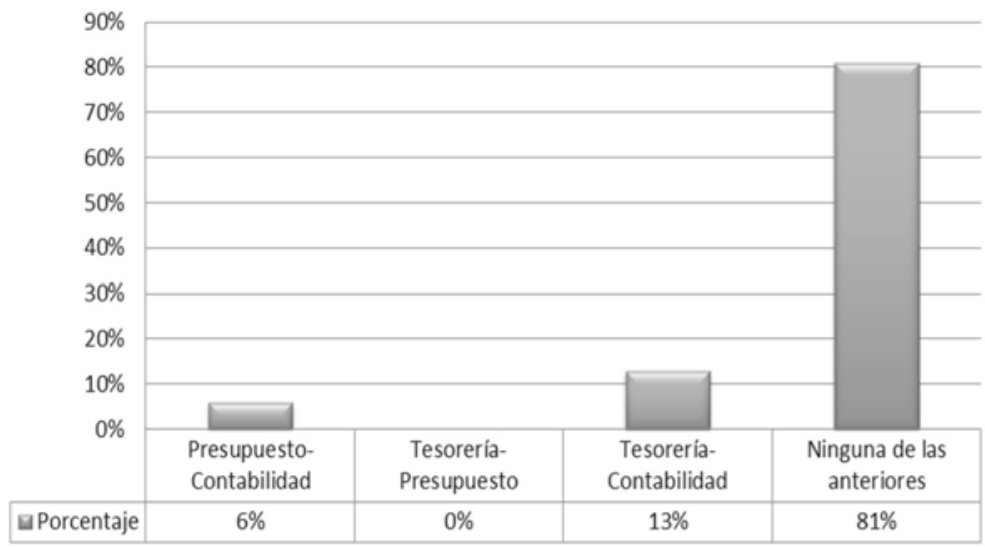

Figura 24. Parametrización y homologación con partidas presupuestales en el software administrativo

Elaboración propia, 2017.

El resultado obedece a que cada una de las personas encuestadas conoce la parametrización, pero del proceso al cual pertenece, porque no existe la homologación que permita la articulación para su respectiva conciliación de los datos arrojados al final de un periodo fiscal. Fue aquí donde el ordenador del gasto hizo mucho énfasis expresando la necesidad de buscar un mecanismo para que la información sea más entendible y fácil de conciliar (Figura 24). 
El personal que se desempeña en el área financiera tiene un nivel de educación avanzado; es idóneo, pero como lo muestra la gráfica, está desmotivado con poca percepción positiva del ambiente de trabajo; no obstante, este análisis se trasladará al área del Talento Humano para ser evaluada como clima organizacional (Figura 25).

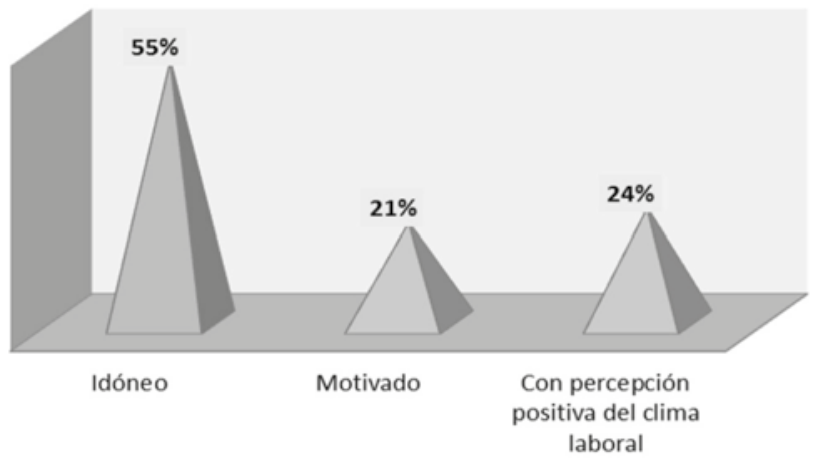

Figura 25. El personal del área financiera es acorde con las especificaciones técnicas que requiere el manual de procedimientos

Elaboración propia, 2017.

La evaluación según la gráfica de la asignación de las funciones realizadas está en las personas, acorde con el perfil profesional (Figura 26)

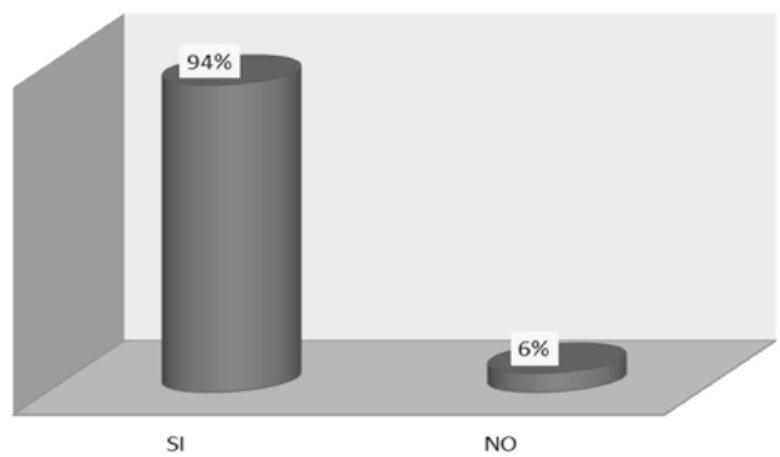

Figura 26. Los procesos a los cargos asignados se encuentran debidamente asignados Elaboración propia, 2017. 


\section{Diagnóstico concluyente}

En el Tecnológico de Antioquia IU, los estados financieros se presentan periódicamente para informar la situación financiera en el momento que lo requieran los diferentes entes de control, desde los procesos de Presupuesto, Contabilidad y Tesorería, pero se verificó que éstos son aislados de acuerdo a los resultados arrojados en la aplicación del instrumento; lo que dificulta la presentación de los informes y la explicación de las inconsistencias encontradas por los entes de control en el momento de hacer la respectiva refrendación del proceso financiero.

El personal que labora en el área financiera es idóneo y capacitado para las labores que desempeña en cada proceso específico, porque a nivel del proceso macro trabaja aisladamente; esto obedece a un manejo cerrado de la información, propio de una cultura establecida a nivel organizacional.

Al presentar información financiera para la toma de decisiones, es oportuna y confiable, pero se hace sobre el tiempo por lo dispendioso de la conciliación porque requiere de una revisión constante y manual de la información desde los diferentes módulos, haciendo vulnerable la manipulación de la información.

La interpretación de la información arrojada es diferente en los tres procesos, dado que cada uno de ellos maneja una normatividad distinta y no existe el interés de las personas en establecer las características que hacen que presupuesto, contabilidad y tesorería no sean iguales.

La Institución Universitaria tiene un software administrativo que permite que se realicen las transacciones contables, presupuestales y de tesorería en línea, pero alimenta cada uno de los módulos en las distintas cuentas que tienen sus respectivas interfaces (según la norma) y no posee un criterio de homologación que permita visualizar la información de manera integrada al momento de conciliar, porque pueden arrojar resultados financieros diferentes por la falta la parametrización de las cuentas contables y de tesorería con las extrapresupuestales; esta situación dificulta la interpretación y la conciliación de la información procesada.

Para mejorar la articulación de los elementos que componen el proceso financiero, se requiere de una herramienta que permita la conciliación de la información objeto de estudio, mediante la parametrización de las cuentas desde el proceso Presupuestal con la debidas interfaces a Tesorería y a Contabilidad con todos 
los rubros, incluyendo partidas no presupuestales, facilitando el cierre de una vigencia fiscal, porque se tiene en cuenta que toda transacción que se realiza en el presupuesto se refleja en la contabilidad y repercute en los ingresos o gastos, por ser operaciones de flujo monetario. Igualmente se deben estandarizar los indicadores de gestión en los procesos de Contabilidad y Presupuesto.

La organización tiene fortalezas en el manejo de la información financiera, pero falta mejorar algunos procesos específicos en esta área de gestión que se convierten en riesgos para el crecimiento institucional.

Otro aspecto importante para tener en cuenta es que hasta el año 2011 existió la cuenta clase $\mathrm{O}$ "Cuentas de presupuesto y tesorería":

(...) que representa las cuentas que identifican el presupuesto de Ingresos y Gastos aprobados para la entidad contable pública en una vigencia fiscal y la correspondiente ejecución que permite conocer la gestión realizada en el cumplimiento de sus funciones de cometido estatal, igualmente está integrada por las cuentas que representan ingresos no aforados, hasta tanto se surta el proceso de incorporación al presupuesto, así como las reservas presupuestales, cuentas por pagar y las vigencias futuras (Resolución, 2007).

Como se evidencia, esta cuenta solo hacía control a los rubros presupuestales, pero no homologaba con la contabilidad general ni con la caja; y al hacer la respectiva comparación entre los tres procesos: Contabilidad, Presupuesto y Tesorería, las diferencias no tenían explicación. Esta cuenta desapareció por la implementación del sistema de la Contaduría General de la Nación Schip y FUT20.

También es importante resaltar situaciones y/o actividades que comprometen la razonabilidad según la Contaduría General de la República, que no solo aplica para el proceso contable sino también para el de Presupuesto y Tesorería, e involucra directamente al personal del área financiera, resaltando que este debe de estar en constante capacitación.

\section{Propuesta - parametrizar - homologar}

Para entender el mecanismo que articulará el proceso financiero, se debe: Identificar los documentos del proceso presupuestal generados por las transacciones automáticas en el sistema con impacto contable y de tesorería como son: los ingresos, las apropiaciones y los pagos. 


\section{Contexto castrimeno.}

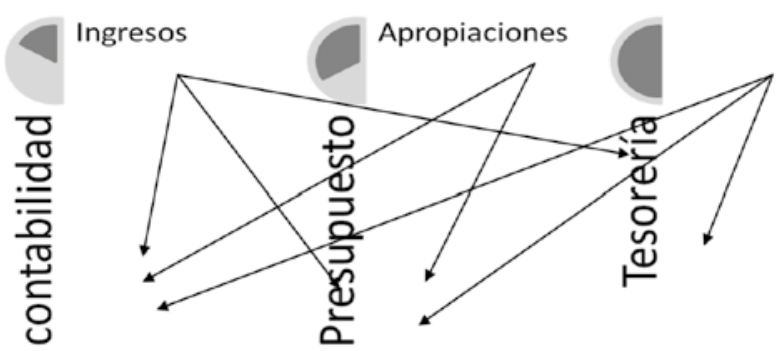

Figura 27. Relación de los procesos financieros

Elaboración propia, 2017.

Conocer los rubros presupuestales de ingresos relacionados con los diferentes conceptos de recursos que se para iniciar los distintos gastos de la institución y los rubros de gastos que contienen los conceptos de las apropiaciones asignadas para el cumplimiento de las funciones como ente público perteneciente a la Administración Central del Departamento de Antioquia (Códigos schip).

Crear el catálogo de cuentas de pagos no presupuestales, que será utilizado con el propósito de facilitar los pagos de operaciones que no tienen apropiación presupuestal, como son las operaciones de tesorería, los acreedores por recaudos que no tienen relación con ingresos, las deducciones o descuentos realizados a terceros conforme a las normas legales que los rigen, entre otros (PUC).

Entender que el catálogo contable es el instrumento que se utiliza en el sistema para reconocer y revelar las transacciones y operaciones financieras realizadas en la ejecución presupuestal y las operaciones de tesorería, entre otras.

Todos los documentos registrados en el sistema tienen los datos necesarios para construir un registro contable con la información complementaria que se requiera, adicional al "debe" y "haber" de la operación denominada Transacción contable. Esta transacción ofrece la posibilidad de encontrar y seguir el rastro a todas las operaciones con impacto contable; localizando internamente el origen de cada una de ellas a través de consultas e informes en el sistema; permitiendo conocer su historia presupuestal o no presupuestal. 


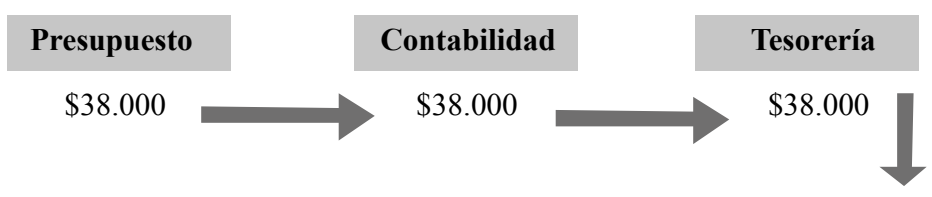

Figura 28. Registro de un documento de ingreso

Elaboración propia, 2017.

La figura muestra un documento registrado en contabilidad, presupuesto y tesorería, con impacto en los tres procesos aumentando los ingresos presupuestales, afectando en el crédito la causación contable y registrando en caja y/o bancos el ingreso real.

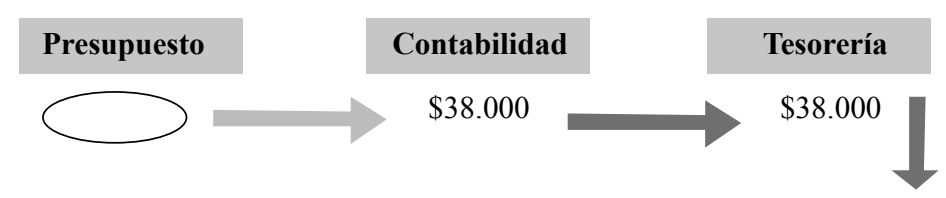

Figura 29. Registro de un documento de ingreso sin interface presupuestal Elaboración propia, 2017.

La figura muestra la falta de registrar el ingreso que afecta la ejecución de los ingresos; pero sí está el registro contable y el de la tesorería; si esto no se detecta fácil para hacer la respectiva corrección, se entregaría una información que al ser auditada no es correcta, hay un faltante.

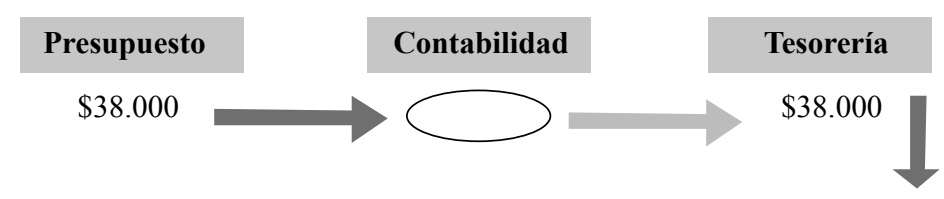

Figura 30. Registro de un documento de ingresos sin interface contable

Elaboración propia, 2017.

Igualmente como en el caso anterior, también se entregaría información incorrecta por el faltante en contabilidad, este tipo de casos se deben de identificar para que los procesos continúen y sea la información coherente con los análisis financieros. 


\section{Contexto cassinus o.}

Para detectar errores como los anteriores es necesario revisar los movimientos presupuestales, los auxiliares de contabilidad y los movimientos de caja diarios; de esta manera se determinará cuál es la transacción faltante y poderla corregir con su respectivo soporte legal, porque, los auxiliares, contienen la estandarización de los registros contables con las diferentes tipologías de las transacciones definidas en el sistema para cada uno de los macroprocesos. Con la parametrización definida no es necesaria la revisión constante porque se homologarán por medio de interfaces todos los documentos que se utilizan en el módulo de la Tesorería con impacto contable y presupuestal.

Una transacción se define como una de las distintas formas de ejecutar el presupuesto o posición de pago no presupuestal utilizando diferentes variables combinadas, tales como: la causación de una obligación con IVA y deducciones, la causación de un gasto sin IVA y con deducciones, la causación de un gasto sin IVA y sin deducciones, pago de un anticipo, el giro para la apertura de una caja menor, el recaudo en efectivo a través de bancos o con títulos, la devolución de ingresos con o sin deducciones, entre otros.

Paso 1. Entrega de factura

\begin{tabular}{cccrr}
\hline FACTURA No & VALOR & IVA & $\begin{array}{c}\text { FECHA } \\
\text { FACTURA }\end{array}$ & TOTAL FACTURA \\
$\mathbf{6 4}$ & $16,700,000.00$ & $2,672,000$ & Dic.05/2012 & $19,372,000.00$ \\
\hline
\end{tabular}

Paso 2. Causación contable

\begin{tabular}{|c|c|c|c|}
\hline Cuenta & CONCEPTO & Débitos & Créditos \\
\hline 14221001 & ACTIVO & 2.672 .000 .00 & \\
\hline 24010101 & PASIVO & & $15,631,200.00$ \\
\hline 24360301 & PASIVO & & $1,837,000.00$ \\
\hline 24362502 & PASIVO & & $1,336,000.00$ \\
\hline 24362710 & PASIVO & & $167,000.00$ \\
\hline 29050201 & PASIVO & & $66,800.00$ \\
\hline 29050202 & PASIVO & & $100,200.00$ \\
\hline 29050203 & PASIVO & & $167,000.00$ \\
\hline 29050205 & PASIVO & & $66,800.00$ \\
\hline 51111104 & GASTO & 16.700 .000 .00 & \\
\hline
\end{tabular}


Paso 3. Registro de obligación presupuestal

\begin{tabular}{lllcc}
\hline & Rubro & \multicolumn{1}{c}{ Descripción } & C-Costo & Valor \\
\hline 1134 & $\mathbf{0 - 1 0 1 0 9 9 9}$ & $\begin{array}{l}\text { SERVICIOS } \\
\text { TECNICOS }\end{array}$ & 103.304 & $19,372,000.00$ \\
\hline
\end{tabular}

Paso 4. Elaboración cheque-Tesorería \$15.631.200

Figura 31. Ejemplo práctico de la causación de una factura de compra

Elaboración propia, 2017.

La diferencia con respecto a cada uno de los procesos es:

En contabilidad, se causa el valor de $\$ 3.740 .800$ que corresponden a retenciones que por Ley se deben de aplicar a los proveedores, como retención en la fuente, industria y comercio y las estampillas, moviendo cuentas del pasivo en el crédito y del activo en el débito como son el gasto y el IVA que es por cobrar. Al mover cada una de estas cuentas se debe tener en cuenta la mecánica de las mismas según el PUC de la Contaduría General de la Nación. Finalmente se genera una cuenta en el pasivo que es realmente lo que se cancelará, o por el cual se hará contablemente el cheque al proveedor $\$ 15.631 .200$ (Ver paso 2).

Al generar la obligación, se genera mediante la cancelación del Registro Presupuestal por el valor del gasto; en este caso el valor total de la factura sin deducciones $\$ 19.372 .000$ (Ver paso 1).

Cuando se elabora el cheque, éste cancela la cuenta por pagar del pasivo contabilizado en el crédito, la obligación presupuestal y se descarga del banco.

Al hacer la articulación de este proceso se deben de cotejar dichas cuentas mediante los movimientos contable, presupuestal y de tesorería.

Si se encuentran diferencias en estos procesos se debe de corregir, porque de lo contrario la información financiera presentada no será coherente con la realidad. Para que no existan diferencias entre los tres procesos que se están verificando de una forma manual, se debe de parametrizar toda la cuenta del pasivo en rubros que se crearán como extrapresupuestales, que serán creadas con fines de articulación de los procesos Paso 1, que contablemente serán las que están en las cuentas del pasivo (Figura 33). 


\section{Contexto cassinus o.}

Entender las condiciones para la homologación a tener en cuenta son la identificación de los conceptos presupuestales comparados con los registros contables de causación y acreedor de ingresos, tipos de operación y retenciones, obligaciones y pagos presupuestales, y pagos no presupuestales que vinculan el código no presupuestal con el código contable.

Otros pagos que incluyen pagos que son realizados contablemente pero que no tienen afecte presupuestal son: deducciones de nómina, la retención en la fuente, las estampillas y de acreedores de ingresos (recaudos para terceros).

\begin{tabular}{rlrr}
\hline \multicolumn{1}{c}{ NIT } & \multicolumn{1}{c}{ CxP } \\
\hline \multicolumn{1}{c}{ Cuenta } & \multicolumn{1}{c}{ Débitos } & \multicolumn{1}{c}{ Créditos } \\
24360301 & Retención en la fuente & $900,397,645$ & $1,837,000.00$ \\
24362502 & Retención de IVA & $900,397,645$ & $1,336,000.00$ \\
24362710 & Industria y Comercio ICA & $900,397,645$ & $167,000.00$ \\
29050201 & Estampilla & $900,397,645$ & $66,800.00$ \\
29050202 & Estampilla & $900,397,645$ & $100,200.00$ \\
29050203 & Estampilla & $900,397,645$ & $167,000.00$ \\
29050205 & Estampilla & $900,397,645$ & $66,800.00$ \\
\hline
\end{tabular}

Figura 32. Cuentas por pagar en la Tesoreria - No presupuestales

Elaboración propia, 2017.

Esta es la principal característica para tenerla en cuenta porque en la tabla anterior muestra causación de cuentas por pagar a terceros, que no están mostrando ejecución presupuestal en el momento, pero que hubo una factura que dio origen a estos pasivos al modificar el presupuesto en la generación de la obligación por el valor total (Paso 1).

Lo anterior muestra cómo se puede dar la conciliación identificando los documentos (factura, cheque, extracto, recibo de caja), clasificándolos de acuerdo al proceso (presupuesto, contabilidad, tesorería), estableciendo las relaciones con las respectivas características (causación, obligación o pago) y homologando los procesos (si tiene impacto contable, presupuestal y de tesorería o viceversa).

Al hacer la respectiva conciliación se debe tener en claro la mecánica de las cuentas y el impacto de los rubros de ingresos y egresos, porque si se confunden, los resultados no serán confiables en los estados financieros y por ende los indicadores de gestión estarán afectados. 


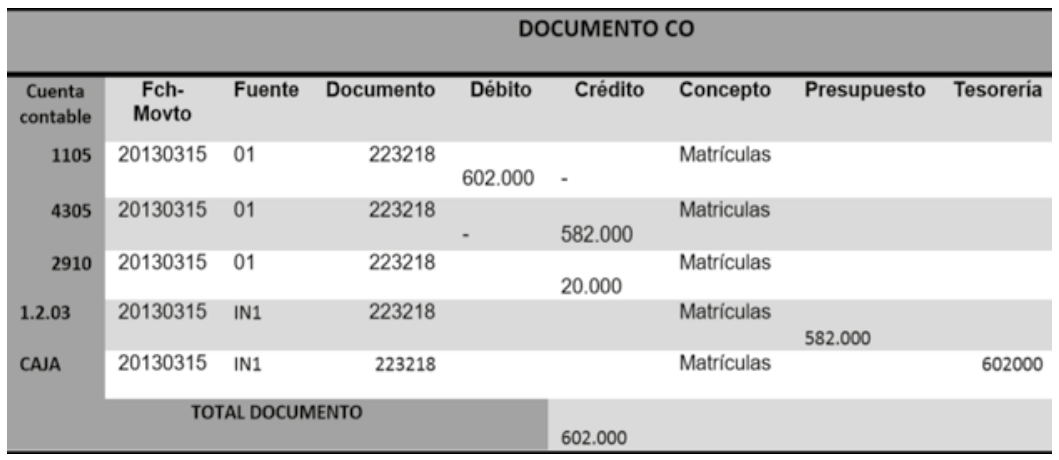

Figura 33. Registro de un documento de ingresos

Elaboración propia, 2017.

El ingreso registrado contablemente en el activo y el pasivo, constituye un ingreso para la Institución Universitaria y un recaudo para terceros respectivamente. En el registro presupuestal solo ingresa lo que está contablemente en el activo, porque el pasivo constituye un valor no presupuestal y en la tesorería se registra el ingreso total generando una cuenta por pagar a terceros.

Los asientos contables manuales son el instrumento mediante el cual se registran las operaciones que no tienen origen presupuestal como las depreciaciones, amortizaciones, provisiones y hechos derivados por otros sistemas que no están incluidos en el SIIF; entre los que se pueden mencionar las operaciones de cartera, las operaciones de crédito público o de financiamiento, entre otras.

También se consideran comprobantes manuales los originados en ajustes a los registros automáticos, cuya modificación es controlada por el sistema, llamados contra asientos; se usan básicamente para corregir errores.

Adicionalmente, en el sistema se registran las transacciones de recaudos originadas en bancos, tomando la información contenida en las cuentas bancarias (Tesorería), sin requerir la búsqueda de los parámetros contables; en razón a que los movimientos bancarios se registran con el cargue de los extractos de las cuentas y estos dejan los datos necesarios para construir el asiento contable y presupuestal.

Todos los documentos generados por servicios prestados a la institución deben de pasar por el proceso Contable y Presupuestal con impacto en la Tesorería. 


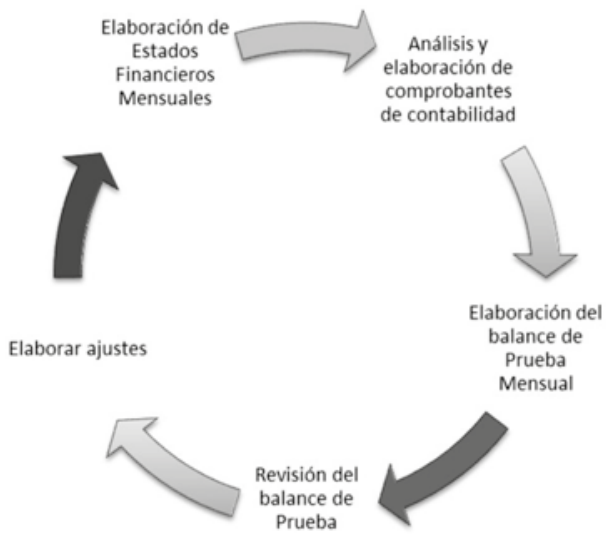

Figura 34. Proceso Contable

Elaboración propia, 2017.

Como lo muestra la Figura 28, la parametrización empezaría desde el proceso presupuestal donde se matricularán los rubros con las respectivas cuentas contables y los bancos.

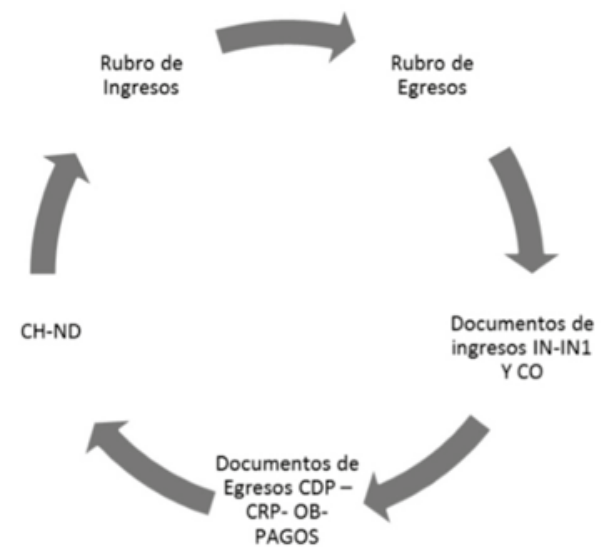

Figura 35. Proceso presupuestal

Elaboración propia, 2017.

La propuesta quedará según la Figura 35 parametrizada y al finalizar una vigencia fiscal los resultados deben ser iguales en los tres elementos que componen el proceso financiero (ejecución presupuestal, balance general y movimiento de caja). 

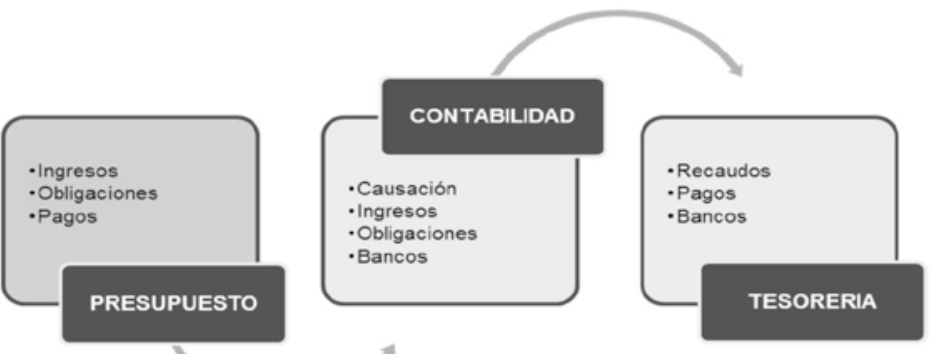

Figura 36. Módulos articulados con la parametrización

Elaboración propia, 2017.

Para entrar a realizar la refrendación de los datos reflejados en la ejecución presupuestal, en los estados financieros y en el movimiento de caja, debe de cumplir con el objetivo de mostrar el efecto de las variaciones en el efectivo durante un periodo, vinculadas a las actividades de operación, inversión y financiación.

Posteriormente, a partir de los asientos manuales y automáticos de los tres procesos, el sistema genera los comprobantes contables respectivos, que se recogen en los libros principales: ejecuciones presupuestales, balance general y movimiento de caja. Estos sirven de base para la generación de los reportes básicos que serán reportados a la Contaduría General de la Nación a través del CHIP y el SCHIP y al Ministerio de Educación Nacional. Así mismo, la información mencionada estará disponible para los organismos de control y los usuarios estratégicos, depurada y revisada mediante la herramienta financiera puesta en marcha.

La herramienta, "El software", una vez construida es la que, de una manera ordenada y predefinida, relacionará las cuentas por medio de interfaces (determinadas) de las transacciones originadas en los distintos procesos, generando los asientos presupuestales, contables y de tesorería automáticos y generará las inconsistencias presentadas, para corregirlas, teniendo en cuenta la respectiva mecánica del proceso ya identificado.

\section{Indicadores para la toma de decisiones en el Tecnológico de Antioquia IU}

Los indicadores tienen el propósito de medir en forma transparente y uniforme la sostenibilidad del Tecnológico de Antioquia IU, a través de solvencia patrimonial, rentabilidad, liquidez y eficiencia operativa; de tal manera que puedan ser fácilmente comparables entre sí. 


\section{Contexto cassinus o.}

Además la evaluación e interpretación de los indicadores financieros y de gestión denominados también indicadores de desempeño deben constituirse en el Tecnológico de Antioquia IU, como una disciplina de autoevaluación que debe hacer periódicamente la alta dirección para que con los resultados obtenidos se tomen los correctivos necesarios o se establezcan políticas de inversión.

La relación entre los tres procesos financieros: Presupuesto, Contabilidad y Tesorería, constituye una herramienta indispensable de análisis y evaluación permanente. Es por esto que se debe tener presente la utilización de cuentas homogéneas que permitan evaluar y calificar objetivamente a la institución universitaria en cualquier momento, histórico o presente; de igual forma estos indicadores no limitan la creación de otras relaciones que la Institución Universitaria Tecnológico de Antioquia y los entes de control, tanto internos como externos, consideren oportuno realizar para analizar aspectos particulares de su desempeño (Tabla 6).

\begin{tabular}{|c|c|c|}
\hline \multicolumn{3}{|c|}{ INDICADORES GESTIÓN } \\
\hline \multirow{19}{*}{\begin{tabular}{l}
\multicolumn{1}{c}{ PRESUPUESTALES } \\
Índice de ejecución de ingresos \\
İndice de ejecución de gastos \\
Índice de recaudación de \\
ingresos del Presupuesto \\
corriente \\
Índice de pagos de gastos del \\
presupuesto corriente
\end{tabular}} & \multirow{4}{*}{$\begin{array}{l}\text { Indicadores de } \\
\text { liquidez }\end{array}$} & FINANCIEROS \\
\hline & & Razón Corriente \\
\hline & & Capital de Trabajo \\
\hline & & Solidez \\
\hline & \multirow{8}{*}{$\begin{array}{l}\text { Indicadores de } \\
\text { Endeudamiento }\end{array}$} & Endeudamiento \\
\hline & & Concentración endeudamiento a largo plazo \\
\hline & & Apalancamiento financiero \\
\hline & & Apalancamiento total \\
\hline & & Indice de sostenibilidad \\
\hline & & İndice de solvencia \\
\hline & & Cobertura Intereses \\
\hline & & Cobertura de deuda \\
\hline & \multirow{7}{*}{$\begin{array}{l}\text { Indicadores de } \\
\text { Actividad } \\
\text { Indicadores de } \\
\text { Rendimiento }\end{array}$} & Rotación de Activos fijos \\
\hline & & Rotación de activos Total \\
\hline & & Rentabilidad Bruta \\
\hline & & Margen Operacional \\
\hline & & Margen Neto \\
\hline & & Rendimiento del Patrimonio \\
\hline & & Rendimiento Activo Total \\
\hline
\end{tabular}

Figura 37. Indicadores de gestión

Elaboración propia, 2017. 


\section{Indicadores de ejecución presupuestaria}

El primer grupo de indicadores está destinado a valorar los resultados de la gestión presupuestaria efectuada, tratando de conocer el grado en que las previsiones definitivas de ingresos han dado lugar a la liquidación de derechos, y los créditos definitivos han producido reconocimiento contable de obligaciones.

Asimismo, se analiza el proceso de conversión en liquidez de los derechos de cobro liquidados y el ritmo de pago de obligaciones; en ambos casos tanto por lo que hace referencia al presupuesto del ejercicio corriente como a presupuestos cerrados.

En esta línea, para el análisis de la gestión presupuestaria efectuada por la Entidad Pública de que se trate, proponemos los indicadores incluidos a continuación.

Índice de ejecución de ingresos: el índice de ejecución de ingresos (IEI) mide el porcentaje de las previsiones definitivas de ingresos que han dado lugar al reconocimiento contable de derechos liquidados; viene dado por la siguiente expresión:

Derechos liquidados netos

$$
\mathrm{IEI}=
$$
$\mathrm{x} 100$

Previsiones definitivas de ingresos: valores para este índice entre el $80 \%$ y el $105 \%$ se consideran satisfactorios; en cambio, valores inferiores alertan sobre la formulación de unas previsiones excesivas de ingresos; práctica no deseable pero demasiado corriente.

Para un análisis completo de la gestión presupuestaria realizada, es conveniente desglosar el índice general de ejecución de ingresos en sus componentes. En efecto, el conocimiento del índice de ejecución de ingresos corrientes, así como del correspondiente a los ingresos por operaciones de capital, o la distinción entre operaciones financieras y no financieras, aporta información relevante para valorar la gestión realizada por la entidad en cuanto a la ejecución de las diferentes categorías de ingresos. 


\section{Contexto cassinten . .}

Índice de ejecución de gastos: el índice de ejecución de gastos (IEG) expresa el porcentaje que suponen las obligaciones reconocidas con cargo al presupuesto de gastos del ejercicio corriente, en relación con el volumen de créditos definitivos; viene dado por la siguiente expresión:

Obligaciones reconocidas netas

$\mathrm{IEG}=$ x100

Créditos definitivos: el índice de ejecución de gastos, que nos muestra el grado en que los créditos definitivos han dado lugar al reconocimiento de obligaciones, también ha de alcanzar valores superiores al $72 \%$.

Sin embargo, para un análisis más detallado del grado de ejecución de los gastos, también resulta conveniente observar el comportamiento por separado de los índices de ejecución de gastos corrientes y de gastos de capital, así como de los índices relativos a las operaciones no financieras y financieras. Efectivamente, el grado de ejecución de cada una de esas categorías de gastos presenta connotaciones diferentes que resulta preciso evaluar. Con relación a los gastos corrientes, el índice correspondiente suele presentar valores elevados, generalmente superiores al $95 \%$, lo que no debe sorprender, dado que la planificación de los gastos de personal, de los gastos en bienes corrientes y servicios, o de los gastos financieros, se puede realizar con un razonable grado de precisión, al tratarse de partidas fácilmente predecibles.

El índice de ejecución de gastos de capital se encuentra, habitualmente, muy alejado de esos niveles. Lo normal es que se sitúe entre el $50 \%$ y el $60 \%$, debido sobre todo al capítulo de inversiones reales que suele presentar valores inferiores al 50\%. La explicación a este hecho hay que buscarla en los dilatados periodos de ejecución de las obras públicas que no suelen terminarse dentro del ejercicio en el que comienzan; esta circunstancia provoca una elevada incorporación de remanentes de crédito. A pesar de esto, no cabe duda de que un volumen de obligaciones reconocidas en relación con los créditos para gastos de inversión presupuestados inferior al $60 \%$, no es en absoluto satisfactorio, lo que puede poner de manifiesto una práctica política muchas veces denunciada, consistente en inflar deliberadamente este capítulo en los presupuestos pretendiendo dar una imagen inversora y dinámica que no se corresponde con la realidad de las cifras. 
Índice de recaudación de ingresos del presupuesto corriente: el índice de recaudación de ingresos (IRI) refleja el porcentaje de derechos liquidados con cargo al presupuesto corriente que han sido cobrados durante el ejercicio presupuestario; viene dado por la siguiente expresión:

Recaudación neta

$\mathrm{IRI}=\underset{\mathrm{x}}{\mathrm{x}} \mathrm{100}$

Derechos liquidados netos: Este indicador mide, por lo tanto, la capacidad de la Entidad Pública para transformar en liquidez los derechos de cobro liquidados y vencidos; es decir, el ritmo de cobro.

En principio, parece deseable que el valor del índice supere el $80 \%$; lo que supondría una razonable conversión en liquidez de los derechos de cobro liquidados.

Índice de pago de gastos del presupuesto corriente: el índice de pago de gastos (IPG) refleja el porcentaje obligaciones reconocidas durante el ejercicio con cargo al presupuesto corriente que han sido pagadas durante el mismo. Viene dado por la siguiente expresión:

Pagos líquidos

$\mathrm{IPG}=$

Obligaciones reconocidas netas

\section{Conclusiones}

La metodología para la elaboración de la herramienta financiera es el apoyo a la gestión gerencial porque permitirá entregar al Sistema Integrado de Información Financiera (SIIF) de los entes de control, informes depurados y revisados del Tecnológico de Antioquia IU, aportando integridad y transparencia al manejo administrativo, en cumplimiento de sus funciones de cometido estatal.

El proceso financiero favorece la estandarización de la operación financiera pública, de acuerdo con la normatividad vigente, logrando que la información sea centralizada. 


\section{Contexto castrimeno.}

La utilización de esta metodología disminuye la incertidumbre en la toma de decisiones y permite proyectar la Institución Universitaria, porque cuenta con la información confiable obtenida bajo un proceso financiero estructurado.

La herramienta permite el seguimiento del acceso y registros efectuados por los diferentes usuarios del sistema, ofreciendo a los auditores la información necesaria sobre las novedades, así como de la seguridad de los registros, porque permite monitorear continuamente las operaciones.

Considerando el plan de la Institución Universitaria y mediante la aplicación de esta metodología, se obtendrá un diagnóstico final de la liquidez, que aportará a la construcción de estrategias para el fortalecimiento institucional.

La aplicación de esta manera de consolidar la información financiera contribuye al mejoramiento continuo de la calidad de la información, participando en la modernización de los entes públicos mediante la implementación de esquemas de análisis financieros y de gestión.

La información financiera refrendada ayuda al sistema de control para que la institución cumpla con las funciones de evaluación de las metas establecidas en el Plan de Desarrollo y/o Plan de Acción mediante el manejo de los indicadores, que muestran la viabilidad institucional.

\section{Referencias}

Andrade, S. (2005). Diccionario de Economía. Lima, Perú: Editorial Andrade.

Barona, B. (1992). Gestión Financiera y Presupuestal en Instituciones del sector social. Cali, Colombia: Publicación IFL.

Contaduría General de la Nación. (2007). Resolución 355 Plan General de la Contaduría General de la Nación. Bogotá, Colombia.

Contaduría General de la Nación. (2006). Resolución 119. Bogotá, Colombia.

Córdoba, M. (2011). Finanzas Públicas. Bogotá, Colombia: ECOE.

Herrera, O. (2009). Finanzas Públicas para el siglo XXI. Medellín, Colombia: Librería Jurídica. 
Méndez, E. (1988). Metodología guía para elaborar diseños de investigación en ciencias Económicas, Contables - Administrativas. Bogotá, Colombia: McGraw-Hill.

Ministerio de Hacienda. (2004). Decreto 2789. Sistema de Información Financiera. Bogotá, Colombia.

Morala, B. (2006). Análisis de entidades públicas mediante indicadores: Instrumento de rendición de cuentas y demostración. Recuperado de http://revpubli.unileon.es/ojs/index.php/Pecvnia/article/view/736/650

Plantillas Mil. (s.f.). Recuperado de http://www.plantillasmil.com/plantillas/ planificacion_empresa/planes_financieros?gclid=CJao64KWpbUCFQ4EnQodexUAjw

Reinoso, F. y Uribe, E. (2009). Los Indicadores de gestión y su relación con la cultura organizacional. Ibagué, Colombia: Grupo Eco. Universidad del Tolima.

Romero, E. (2010). Presupuesto Público y Contabilidad Gubernamental. Bogotá, Colombia: ECOE.

\section{Para citar este artículo:}

Castrillón, D. (2017). Metodología para la elaboración de herramientas articuladoras de procesos financieros en entidades públicas. Estudio de caso. En-Contexto, 6(9), 119-153. 